\title{
D. Warwick, R. Dunn, E. Melikyan, J. Vadher (eds), Oxford specialist handbooks in surgery-hand surgery
}

\author{
Oxford Medical Publications, 2009, 635 pp, black and white diagrams \\ (ISBN 9780199227235)
}

\author{
Zeeshan Ahmad
}

Received: 3 February 2010 / Accepted: 8 February 2010/Published online: 6 March 2010

(C) Springer-Verlag 2010

This book is a must for any plastic surgery and orthopaedic surgery trainee, as well as for physiotherapists and occupational therapists. It covers most if not all aspects of hand surgery from assessment and examination to rehabilitation and splinting. It deals with acute injuries and what to do in the emergency department, as well as chronic clinical conditions, and how best to manage them in the outpatient setting. This set up in the clear and concise style of other books in the Oxford Specialist Handbooks in Surgery series, with the usual clear layout. The topics are arranged addressing areas such as bony injuries, soft tissue reconstruction, hand infection and nerve injuries to mention but a few. With useful diagrams interspersed within an easily readable text, this book is an ideal supplement to a larger text for "on the job" use and learning. Perhaps future editions could include radiographs which highlight normal anatomy and variations thereof, as well as pathological findings plus intraoperative photographs which may provide a significant visual stimulus for the reader. Overall, this book is an excellent addition to this series and is a must-have for anyone who deals with hand problems. 